\title{
Computational fluid dynamics applied to gas-liquid contactors
}

\author{
E. Delnoij, * J. A. M. Kuipers and W. P. M. van Swaaij \\ Department of Chemical Engineering, Twente University. P.O. Box 217. \\ 7500 AE Enschede, The Netherlands
}

(Accepted I July 1997)

\begin{abstract}
In this paper a 'hierarchy of models' is discussed to study the fluid dynamic behaviour of gas-liquid bubble columns. This "hierarchy of models" consists of a Eulerian Eulerian two fluid model, a Eulerian-Lagrangian discrete bubble model and a Volume Tracking or Marker Particle model. These models will be briefly reviewed and their advantages and disadvantages will be highlighted. In addition, a mixed Eulerian Lagrangian model and a volume tracking model, both developed at Twente University, will be discussed. Some selected results obtained with these models will be presented with emphasis on the results obtained with the volume tracking model. Finally, a brief discussion on advanced experimental techniques, which reflect the recent progress in experimental fluid dynamics. will be presented. (c) 1997 Elsevier Science Ltd
\end{abstract}

Keywords: Bubble columns; CFD: multi-phase flow: $\mathrm{VOF}$

\section{INTRODLCTION}

Bubble columns find frequent application in the process industries due to their relative simple construction, low operating costs, excellent heat transfer characteristics to immersed surfaces and the ease with which the liquid residence time can be varied (Shah et al., 1982). However, many important fluid dynamical aspects of the prevailing gas-liquid two-phase flow in bubble columns are still poorly understood. despite their frequent use in a variety of industrial processes. This unsatisfactory state of the art has led to an increased interest in recent years in detailed modelling of bubble columns, on basis of the hydrodynamic equations of change, and in the development of advanced experimental tools.

When one develops detailed fluid dynamic models for gas-liquid bubble columns it is important to consider the various hydrodynamic phenomena associated with these gas "liquid two-phase flows and their respective length scales. These length scales typically range from several meters (the overall liquid circulation) down to the Kolmogorov scales of turbulence. Moreover, in a bubble column, bubble diameters typically range from $\mathrm{O}\left(10^{-3} \mathrm{~m}\right)$ to $\mathrm{O}\left(10^{-1} \mathrm{~m}\right)$, and bubble shapes range from spherical to spherical cap, depending on the flow regime prevailing in the column and the physical properties of the liquid. Finally, bubble columns encountered in industry differ substantially

* Corresponding author. E-mail: e.delnoij(a)ct.utwente.nl. in size and geometry (sparged bubble columns, air lift reactors).

From this introduction, it is evident that it is extremely difficult to develop a generalized CFD model that can be successfully applied to study the fluid dynamics of bubble columns in all aforementioned situations. Therefore, it is appropriate to employ a 'hierarchy of models' to study the dynamic behaviour of bubble columns and the associated dynamics of the bubbles. The size of the bubble column, the length scales of the hydrodynamic phenomena of interest and the regime in which the bubble column is operated determine the most appropriate model for the problem at hand.

This 'hierarchy of models' concept employs different CFD models to study, for instance, the dynamic behaviour of an industrial bubble column, or to study the detailed flow phenomena encountered during bubble coalescence. Moreover, the CFD model used to study the time-dependent behaviour of a bubble column operated in the homogeneous regime differs from the model used to study a column operated in the heterogeneous regime. In a bubble column operating in the homogeneous regime, it is required to solve for the time-dependent motion of large amounts of (nearly) spherical gas bubbles rising through the liquid. In a bubble column operating in the heterogencous regime however, it is also important to model the behaviour of large, deformable, gas bubbles. This implies that one has to account for the changes in topology of the gas-liquid interface. Clearly, this requires a different type of model than the type used in 
simulating the behaviour of a column operating in the homogeneous regime.

\section{MODELLING BUBRLE COLUMNS: AN OVERVIEW}

A 'hierarchy of models' that can be used to study the hydrodynamic behaviour of gas-liquid bubble columns typically consists of Eulerian-Eulerian two fluid models, Eulerian-Lagrangian models and Volume Tracking or Marker Particle models.

\subsection{Eulerian-Eulerian two fuid models}

The Eulerian-Eulerian two fluid model uses the volume averaged mass- and momentum conservation equations to describe the time-dependent motion of both the gas and the liquid phase. For multiphase isothermal systems involving laminar flow, these volume-averaged conservation equations are respectively given by

$$
\begin{gathered}
\frac{\partial \rho_{k}}{\partial t}+\nabla \cdot \rho_{k} \mathbf{u}_{k}=R_{k} \\
\frac{\partial \rho_{k} \mathbf{u}_{k}}{\partial t}+\nabla \cdot \rho_{k} \mathbf{u}_{k} \mathbf{u}_{k}= \\
+\varepsilon_{k} \nabla P-\nabla \cdot \varepsilon_{k} \tau_{k}+\sum_{i=1}^{N} \mathbf{M}_{k l} \\
+R_{k} \mathbf{u}_{k}+\mathbf{S}_{k}+\rho_{k} \mathbf{g}
\end{gathered}
$$

where $\rho_{k}, \mathbf{u}_{k}, \varepsilon_{k}$ and $\tau_{k}$ represent, respectively, the macroscopic density, velocity, volume fraction and viscous stress tensor of the $k$ th phase, $p$ the pressure, $R_{\mathrm{k}}$ a source term describing mass exchange between phase $k$ and the other phases, $\mathbf{M}_{k l}$ the interphase momentum exchange term between phase $k$ and phase $l$ and $\mathbf{S}_{\boldsymbol{k}}$ a momentum source term of phase $k$ due to external forces other than gravity.

A two fluid model will typically be used to study the large-scale fiow structures prevailing in industrial bubble columns because of its computational efficiency (compared to, for instance, Eulerian-Lagrangian models). A disadvantage of a Two Fluid model is the need for appropriate closure laws for the interphase transport of mass, momentum and heat. The correct form of these closure laws is still being debated. Also, care must be taken to limit numerical diffusion, for instance, by applying the TVD scheme instead of the UPWIND scheme for the finite-difference approximation of the convective fluxes (Sokolichin et al., 1997).

In recent years, several authors (Gasche et al., 1990; Torvik and Svendsen, 1990; Ranada, 1992; Grienberger and Hofman, 1992; Sokolichin and Eigenberger, 1994; Hjertager and Morud, 1995 and Sokolichin et al., 1997) have contributed to the development of two fluid models for gas-liquid two-phase flow. Studies with this type of model have clearly revealed the intrinsic time-dependent behaviour of gas-liquid bubble columns, and thus, demonstrated the necessity to use dynamic models.

\subsection{Eulerian-Lagrangian models}

In dispersed gas-liquid two-phase flows an alternative to the complete continuum representation is pos- sible by adopting a Lagrangian description for the dispersed phase. If such a Lagrangian description is used to represent the dispersed phase, for each individual bubble (or particle or droplet) an equation of motion is solved:

$$
m_{i} \frac{\mathrm{d} \mathbf{v}_{i}}{\mathrm{~d} t}=\sum \mathbf{F}_{i}
$$

where $m_{i}, v_{i}$ represent, respectively, the mass and velocity of the $i$ th particle and $\sum F_{i}$ the sum of the forces acting on the $i$ th particle. Forces due to gravity, drag, virtual mass and vorticity in the continuous phase can be included in this term. The bubble position can be calculated using:

$$
\frac{\mathrm{d} \mathbf{x}_{i}}{\mathrm{~d} t}=\mathbf{v}_{i}
$$

The advantages of this mixed Eulerian-Lagrangian approach are its greater generality and flexibility with respect to the incorporation of microscopic transport phenomena: bubble dynamics can be described in detail, a bubble diameter distribution can easily be incorporated, direct bubble-bubble interactions can be accounted for as well as hydrodynamic interaction between neighbouring bubbles. Additionally, twoway coupling between the gas and the liquid phase can be embedded in the model. The most important disadvantage of a mixed Eulerian-Lagrangian approach is its relatively high (compared to completely Eulerian approaches) computational load. A Eulerian-Lagrangian model is typically used to study hydrodynamic phenomena that can only be described with great difficulty using a two fluid model (i.e. direct bubble-bubble interaction). Additionally, a Eulerian-Lagrangian model can, to a certain extent, assess the validity of the closure laws used in the two fluid models.

Trapp and Mortensen (1993) and Lapin and Lübbert (1994) conducted pioneering work in this field. Additionally, mixed Eulerian-Lagrangian models have been developed by Devanathan et al. (1995), Sokolichin et al. (1997) and Delnoij et al. (1997a). Although promising results have been obtained in recent years, there still exists disagreement on fundamental issues such as the correct description of the forces acting on a single bubble and the effect of other bubbles on these forces. In this area much fundamental work remains to be done. Moreover, it is very important to extend the mixed Eulerian-Lagrangian approach to the churn-turbulent or heterogeneous bubble regime because this flow regime is frequently encountered in industrial bubble columns. This implies that a model has to be developed that can simultaneously deal with 'large' bubbles and 'small' bubbles. In this respect a model that combines the features of a Volume Tracking method and the mixed Eulerian-Lagrangian method deserves attention. Last but not least, the incorporation of turbulence effects is still problematic and should receive more attention in the future. 


\subsection{Volume Tracking and Marker Particle models}

In both the two-fluid model and the EulerianLagrangian model, the resolution with which the liquid velocity field is resolved is small compared to the size of the bubbles. However, small-scale structures in the liquid (i.e. vortices shed from rising gas bubbles) govern various phenomena encountered in bubble columns, such as bubble coalescence and changes in the topology of the gas-liquid interface. To resolve the time-dependent motion of a gas bubble in a liquid, a Volume Tracking method or a Marker Particle method such as the MAC (Welch et al., 1965) method has to be used to account for possible bubble coalescence and topology changes of the gas-liquid interface. These methods use the NavierStokes equations to resolve the gas-phase and the liquid-phase velocity fields. The various Volume Tracking methods (Nichols et al., 1980; Hirt and Nichols, 1981; Youngs, 1982 and Rudman, 1997) use a 'colour' function $F$ to distinguish between the gas and the liquid phase, whereas Marker Particle methods such as the MAC method, use marker particles to track the time-dependent motion of the liquid phase. These Volume Tracking/Marker Particle methods can typically be used to provide in depth data on bubble coalescence, bubble break up and the shapes and sizes of bubbles under the prevailing flow conditions and physical properties of the liquid. These data can subsequently be used to assess the validity of the closure models used in two fluid models or to assess the validity of collision models and hydrodynamic interaction models in Eulerian Lagrangian type of models.

The dynamics of individual bubbles have been studied extensively in literature using various CFD approaches (Ryskin and Leal, 1984a- $c$ ), Tomiyama et al. (1993) and Hoffman and van den Boogaard (1995). Ryskin and Leal solved the Navier-Stokes equations for the liquid flowing around a deformable bubble on an orthogonal curvilinear coordinate system, which was constructed numerically and continuously adjusted to fit the shape the bubble attained during its rise through the liquid. Tomiyama et al. and Hoffman et al., respectively, used the VOF method (Hirt and Nichols, 1981) and the finiteelement-based SEPRAN package (Cuvelier t't al., 1986). Tomiyama et al. (1993) applied the VOF method to analyse the motion of a single gas bubble rising in a liquid. They were able to show that the shape and terminal velocities of the gas bubbles could be predicted satisfactorily over a wide range of Eötvös and Morton numbers. Recently, Lin et al. (1996) applied the VOF method to study the timedependent behaviour of bubbly flows and compared their computational results with experimental data obtained with a particle tracking velocimetry (PTV) technique.

\section{EXPERIMENTAL TECHNIQLES}

Experimental validation of CFD results is a prerequisite for widespread acceptance of CFD in the chemical engineering community, especially concerning applications of CFD to multiphase flows. Because CFD models usually provide very detailed information on the temporal and spatial distribution of key variables such as volume fractions and phase velocities, very advanced experimental techniques have been developed to obtain experimental data. Some of these techniques, which reflect the recent progress in experimental fluid dynamics will subsequently be discussed in more detail

Point-measuring techniques such as hot-wire anemometry (HWA) and laser-doppler anemometry (LDA) cannot give information on the instantaneous spatial structure of the flow. Point-measuring techniques are inadequate, and more advanced techniques are required, in situations where one is interested in the dynamics of coherent structures, as encountered in, e.g. turbulent single-phase flows and dispersed gas--liquid two-phase flow.

\subsection{Particle image velocimetry}

A very powerful class of velocity measuring techniques termed 'pulsed light velocimetry' has become available in experimental fluid dynamics. These techniques typically measure the motion of small, marked regions of a fluid by observing the locations of the images of the markers at two or more times. The velocity is obtained from the ratio of the observed displacement $\Delta x$ and the time interval $\Delta t$ separating the subsequent observations of the marker images:

$$
\mathbf{u}=\frac{\Delta \mathbf{x}}{\Delta t} .
$$

The marker fluid parcels can consist of small particles, bubbles or droplets but can also be generated in situ by activating the molecules that make up the fluid with a laser beam, causing the molecules to fluorescence (Gharib et al.. 1985).

A very powerful method, belonging to the class of PLV techniques, to obtain quantitative information on the instantaneous structure of the flow is particle image velocimetry (PIV) and its digital counterpart (DPIV). In these techniques, a suitably chosen number of neutrally buoyant tracer particles are suspended in the fluid and, subsequently, a section of the flow is illuminated with the aid of a laser whereby the tracer particles become visible. By making (high resolution) video recordings of the illuminated section of the flow and subsequent processing of the digitized images using advanced statistical techniques (Westerweel. 1993) the instantaneous flow field of the fluid in the test section can be obtained. Due to this ability. DPIV can provide detailed information on the dynamics of coherent flow structures which is typically also the type of information obtained from (advanced) CFD models. For further details the interested reader is referred to the review paper of Adrian (1991) and Westerweel (1993) and the references cited therein. 
At low seeding densities, PIV is commonly called particle tracking velocimetry (PTV). Whereas PIV determines the average displacement of all tracer images within an interrogation area using a statistical technique, PTV determines the displacement of each individual image of a tracer particle using a matching technique. This PTV technique has been used to study the flow structure in bubble columns (Reese and Fan, 1994 and Lin et al., 1996). A specific complication here is caused by the presence of the gas bubbles. On basis of a prior knowledge of the size distribution of the tracer particles and the gas bubbles it is possible to discriminate bubbles from particles and thus, phase-specific post-processing of the images can be undertaken by which the flow pattern of bubbles and the liquid can in principle be obtained. Particle tracking velocimetry has also been applied (Chen and Fan, 1992) to study the flow structure in three-dimensional gas-liquid-solid fluidized beds.

\subsection{Radio-active particle tracking methods}

In radio-active particle tracking methods the motion of a (radio-active) particle is tracked in time using a set of detectors with a suitable geometrical arrangement where the dynamic behaviour of the particle is (considered) similar to that of the phase under consideration. Devanathan et al. (1990) employed their computer aided radio-active particle tracking (CARPT) technique to obtain information on the three-dimensional path of a particle in a bubble column. The CARPT technique measures the local displacement of the tracer particle from which its local instant velocity can be computed. Moreover, ensemble averaged velocities and turbulence quantities can be calculated from the CARPT data, after acquiring these data for a sufficient length of time. In principle, this technique can also be applied to other multiphase reactors such as gas fluidized or liquid-fluidized beds and threephase fluidized beds. Larachi et al. (1996) applied their radioactive particle tracking ( $R P T$ ) technique to determine the time-averaged solids velocity in a threephase fluidized bed.

\section{CFD MODELS FOR GAS-LIQLIID BLBBLE COLL MNS DEVELOPED AT TWENTE LNIVERSITY}

In this paper we will present two models developed at Twente University as part of the previously introduced 'hierarchy of models' concept. The two models are a Eulerian-Lagrangian model and a Volume Tracking model based on the volume-of-fluid approach originally developed by Hirt and Nichols (1981). The Eulerian Lagrangian model has been developed specifically to describe the time-dependent behaviour of a bubble column operated in the homogeneous regime. Whereas the volume-of-fluid (VOF) model has been developed to study the dynamics of multiple, deformable gas bubbles in liquids. The $\mathrm{em}$ phasis of the paper and the results presented herein will be on the volume-of-fluid model: a more detailed description of the Eulerian Lagrangian model can be found in Delnoij et al. (1997a).

\subsection{The Eulerian Lagrangian model}

Delnoij et al. (1997a) have developed a detailed, two-dimensional Eulerian Lagrangian model for a gas liquid bubble column operating in the homogeneous regime. The model describes the timedependent motion of small spherical gas bubbles in a Newtonian liquid and accounts for all relevant forces acting on a bubble. The model assumes that the force $F_{\text {total }}$ acting on a non-deformable spherical bubble that rises in an unsteady, and non-uniform liquid flow field is composed of separate and uncoupled contributions from pressure gradient. drag, virtual or added mass, vorticity and gravity (Auton, 1983):

$$
\mathbf{F}_{\text {total }}=\mathbf{F}_{p}+\mathbf{F}_{D}+\mathbf{F}_{V M}+\mathbf{F}_{l .}+\mathbf{F}_{G} .
$$

The Eulerian-Lagrangian model, or discrete bubble model. describes the liquid-phase hydrodynamics with the well-known volume-averaged Navier-Stokes equations. It accounts for exchange of momentum between the gas and the liquid phase via a source term in the momentum equations, and it describes direct bubble bubble interactions in detail using a collision model. For details concerning this model and the expressions used for the various forces acting on a bubble, the interested reader is referred to Delnoij et al. (1997a).

\subsection{The colume-of-fluid ( $V O F)$ model (Delnoij et al., 1997b)}

Within the "hierarchy of models' concept a twodimensional VOF model has been developed to describe the time-dependent motion of deformable gas bubbles rising in a quiescent Newtonian liquid. This VOF model resolves the transient motion of the gas and the liquid phase using the Navier-Stokes equations, and accounts for the topology changes of the gas -liquid interface induced by the relative liquid motion. The finite-difference VOF model uses a donor-acceptor algorithm, originally developed by Hirt and Nichols (1981), to obtain, and maintain, an accurate and sharp representation of the gas-liquid interface.

4.2.1. Advancing the gas-liquid interface in time. The VOF method defines a fractional volume or 'colour' function $F(\mathbf{x}, t)$ that indicates the fraction of a computational cell filled with liquid. In particular, a unit value of $F$ indicates a computational cell completely filled with liquid, whereas a zero value of $F$ indicates a cell containing only gas. Obviously, cells with $F$ values between zero and one contain a gasliquid interface. The model solves the scalar advection equation for the quantity $F$ : this equation states that $F$ moves with the fluid:

$$
\frac{\mathrm{D} F}{\mathrm{D} t}=\frac{\hat{\mathrm{C}} F}{\mathrm{\partial} t}+(\mathbf{u} \cdot \nabla) F=0 .
$$



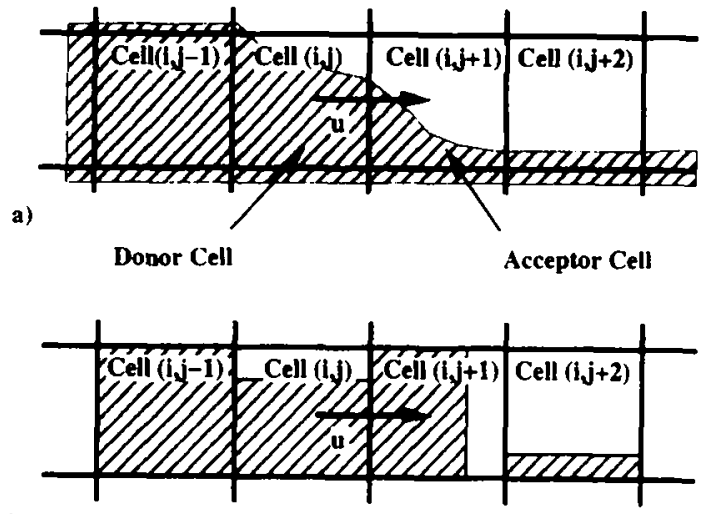

b)

Fig. 1. Detection of donor and acceptor cell. True interface orientation a) and approximate interface according to the VOF method due to Hirt and Nichols (1981).

The finite-difference approximation of this advection equation relates the new time level $F$ value to its previous value and to the fluxes of the quantity $F$ through the cell faces (four in two-dimensions and six in three-dimensions). To calculate these fluxes, the donor-acceptor algorithm is employed to avoid averaging (inherent in convective flux approximations) across a discontinuity with respect to $F$, and therefore, across the gas-liquid interface. This averaging leads to an undesirable computational smearing of the $F$ function, causing the interface to lose its sharp, crisp nature.

To calculate the $F$-flux across a cell face, the donor-acceptor algorithm initially detects the donor and the acceptor cell, depending on the sign of the normal velocity at the cell face under consideration (see Fig. 1). The amount of $F$ fluxed from the donor cell [cell $(i, j)$ in Fig. 1] to the acceptor cell [cell $(i, j+1)$ in Fig. 1] during a time interval $\delta t$ is given by

$\left\langle u_{x} F\right\rangle_{t, j-12} \cdot \delta t=\operatorname{MIN}\left\{F_{A D}\left|u_{x_{1, \ldots},}\right| \delta t+\mathrm{CF} ; F_{D} \cdot \delta x_{\}}\right.$

where

$C F=\operatorname{MAX}\left\{\left(1.0-F_{A D}\right)\left|u_{x_{x, 1}, 1}\right| \delta t-\left(1.0-F_{D}\right) \delta x ; 0.0\right\}$.

In eqs (8) and (9) $F_{A D}$ refers to either $F_{A}$ or $F_{D}$ depending on the orientation of the gas-liquid interface relative to the direction in which $F$ is fluxed. The acceptor cell value $\left(F_{A}\right)$ is used when the gas-liquid interface is advected mostly normal to itself, otherwise the donor cell value is used. However, the acceptor cell value for $F$ is used as an estimator for $F_{A D}$, whatever the interface orientation, when the acceptor cell is empty of $F$ or when the cell upstream of the donor cell is empty of $F$.

The VOF method as discussed by Hirt and Nichols (1981) applies a rather crude approximation to the orientation of the gas- liquid interface; an interface is specified as either horizontal or vertical depending on the prevailing direction of the surface normal. This surface normal, which points in the direction in which $F$ changes most rapidly, is calculated using a nine-cell stencil. Once the interface orientation is known, the algorithm decides whether $F_{A}$ or $F_{D}$ is used as an estimator for the flux $F_{A D}$. Finally, the flux through a cell face can be determined using eqs (8) and (9). The new time level $F$ values for every computational cell can, subsequently, be determined using the finite-difference equivalent of eq. (7).

4.2.2. Governing equations. The VOF model uses the mass and momentum conservation equations for incompressible fluids, to describe the fluid dynamics of both the gas and the liquid phase

$$
\nabla \cdot \mathbf{u}=0
$$

$$
\frac{\hat{\rho} \boldsymbol{u}}{\hat{c} t}+\nabla \cdot \rho \mathbf{u} \mathbf{u}=-\nabla P-\nabla \cdot \tau+\rho \mathbf{g}+\mathbf{F}_{\mathbf{S F}}
$$

The continuum surface force (CSF) model, originally developed by Brackbill et al. (1992), is used to model the force due to surface tension acting on the gasliquid interface. A similar approach is used to account for forces acting on the liquid due to wall adhesion.

The CSF model replaces the surface force due to surface tension with a continuous (or volume) force $\left(F_{S F}\right)$ acting on all fluid elements in the interface transition region

$$
\mathbf{F}_{\mathrm{SF}}=2 F(\mathbf{x}, t) \sigma \kappa(\mathbf{x}, t) \mathbf{n}(\mathbf{x}, t) .
$$

In eq. (12) $\kappa$ represents the local surface curvature, which can be calculated using the normal to the gas-liquid interface. Clearly, to enhance the accuracy of the CSF model, the VOF model has to maintain as compact and sharp an interface as possible (preferably $\mathrm{O}(\delta x))$

4.2.3. Boundary conditions and numerical solution. The boundary conditions required to solve the model equations are incorporated in the model using the flag matrix concept. This concept, also used by Kuipers et al. (1993), allows a variety of boundary conditions to be set for each individual computational cell by specifying the value of the cell flag $f(i, j)$. Table 1 provides an overview of the available cell flags and the corresponding boundary conditions. To account for the forces acting on the liquid due to wall adhesion. a static contact angle has to be provided. This contact angle, is used to calculate the surface normal at the wall. Figure 2 depicts a typical grid lay-out used in many simulations presented in this paper. To study both bubble formation and bubble rise, a bubble column containing a quiescent liquid was used as initial condition. Starting at $t=0.0 \mathrm{~s}$ gas was fed to the column through one or more orifices, at a specified flow rate.

The volume-of-fluid model, as described in the previous sections has been implemented in a computer code written in $C$. The code solves the Navier-Stokes 
Table 1. Cell flags and corresponding cell types used in defining boundary conditions

\begin{tabular}{ll}
\hline$f(i, j)$ & Physical meaning of cell $(i, j)$ \\
\hline 1 & $\begin{array}{l}\text { Interior cell, no boundary conditions have to } \\
\text { be specified }\end{array}$ \\
2 & $\begin{array}{l}\text { Impermeable wall, free-slip boundary } \\
3\end{array}$ \\
4 & Impermeable wall, no-slip boundary \\
& Gas phase influx cell, normal velocity has to \\
5 & Pe specified \\
6 & Continuous outflow cell, free-slip boundary \\
7 & Impermeable floor, free-slip boundary \\
8 & Impermeable floor. no-slip boundary \\
9 & Corner cell. no boundary conditions have to \\
& be specified
\end{tabular}

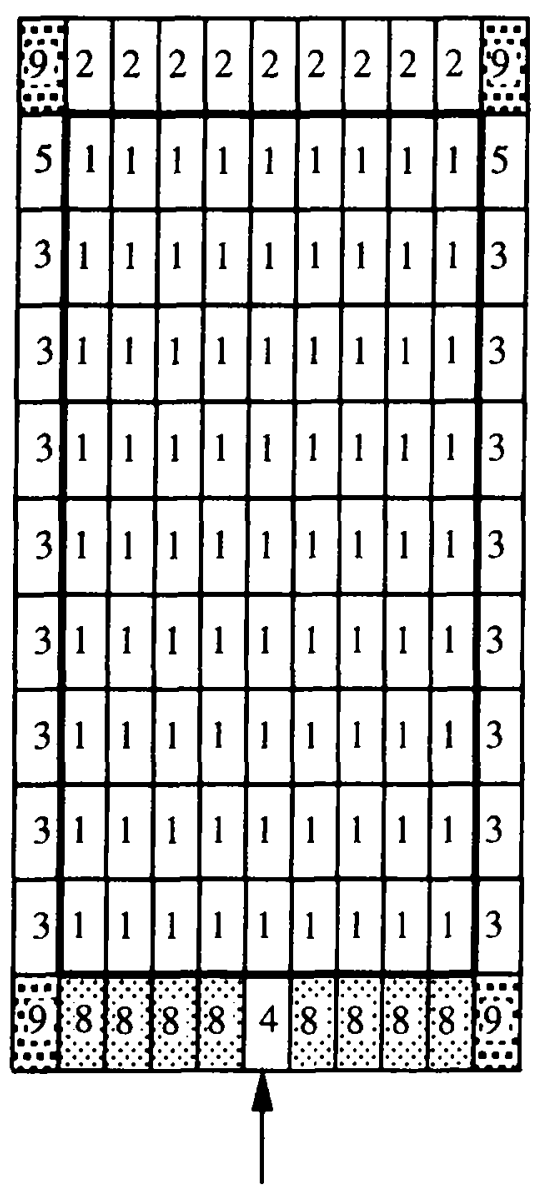

Fig. 2. Typical grid lay-out used during most of the simulations with the VOF model presented in this paper.

equations and advects the gas-liquid interface in time by solving transport eq. (7) and the associated boundary conditions for each computational cell. To solve a typical problem involving a single gas bubble rising during $1.0 \mathrm{~s}$ in a liquid, using a computational mesh of
$100 \times 150$ cells, $8 \mathrm{~h}$ dedicated CPL time is required on a Silicon Graphics Indigo ${ }^{2}$ workstation. Approximately $60 \%$ of the CPU time used by the VOF code is required to solve the $\mathrm{Naiver-Stokes} \mathrm{equations,} \mathrm{where-}$ as about $30 \%$ of the CPU time is used to advect $F$.

\section{SELECTED RESULTS AND DISCUSSION}

In the present paper we have introduced the hierarchy of models' concept employed at Twente University to model the hydrodynamic behaviour of gasliquid bubble columns. As part of this concept, two separate models have been discussed; i.e. a Eulerian Lagrangian model and a volume-of-fluid model. In this section results obtained with the VOF model will be discussed. Additionally, the results obtained with the Eulerian Lagrangian model will be briefly reviewed.

\subsection{Eulerian-Lagrangian model}

Delnoij et al. (1997a) used their discrete bubble model to simulate two experiments reported by Becker et al. (1995), one for a large superficial gas velocity and another one for a small superficial gas velocity. Becker et al. conducted experiments in a pseudo two-dimensional bubble column equipped with a gas distributor section containing five, individually controllable porous plates. Becker et al., fed gas (air) to the column (containing water) through only one of the five porous plates during their experiments.

Figure 3 depicts a sequence of snapshots showing both the instantaneous configuration of the bubbles and the associated flow ficld in the liquid phase at the large superficial gas velocity. In accordance with the observations by Becker et al., the model predicts the development of a powerful liquid circulation which pushes the bubble swarm firmly towards the left wall of the column. This strong liquid circulation is induced by the large number of bubbles which rise through the column.

At lower superficial gas velocities Becker et al., observed a remarkably different flow pattern in their bubble column. Contrary to the experiment with the large superficial gas velocity, the bubble swarm was observed to move upwards in a meandering manner. Several liquid circulation cells were reported which change their location and size continuously. The flow was observed to be highly dynamic with a period of oscillation of the vertical velocity of approximately 41 s. Figure 4 depicts a sequence of snapshots of the behaviour of the bubble plume and the associated liquid velocity field at the lower superficial gas velocity, as calculated by our model. The mcandering behaviour and the main liquid-phase flow characteristics reported by Becker et al., could clearly be reproduced by our model. However, the period of oscillation, calculated by the discrete bubble model, was found to be approximately $30 \mathrm{~s}$. This difference between our computation and the experimental results reported by Becker $e t$ al., is most likely due to the two-dimensional nature of our model. 

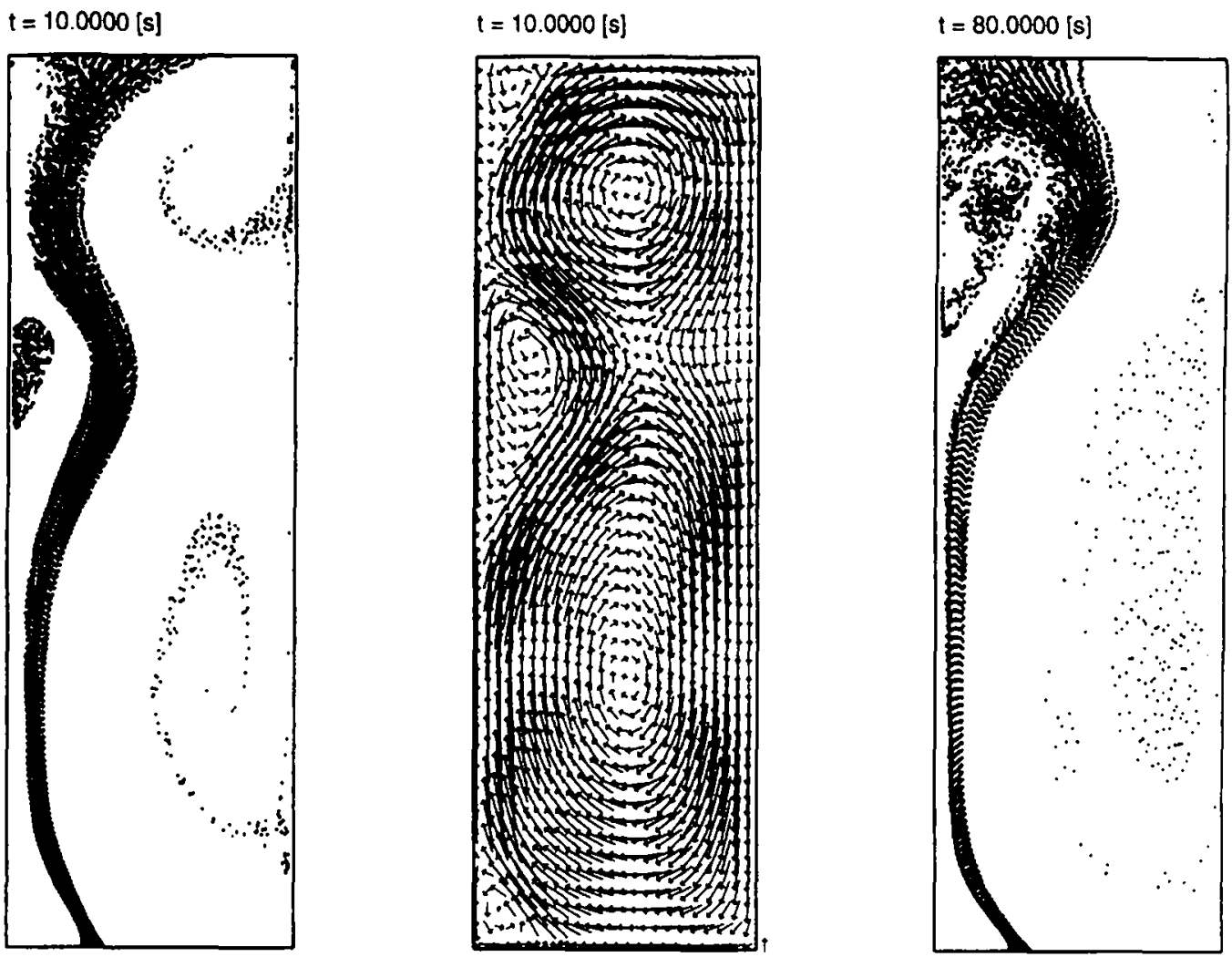

$t=80.0000[s]$
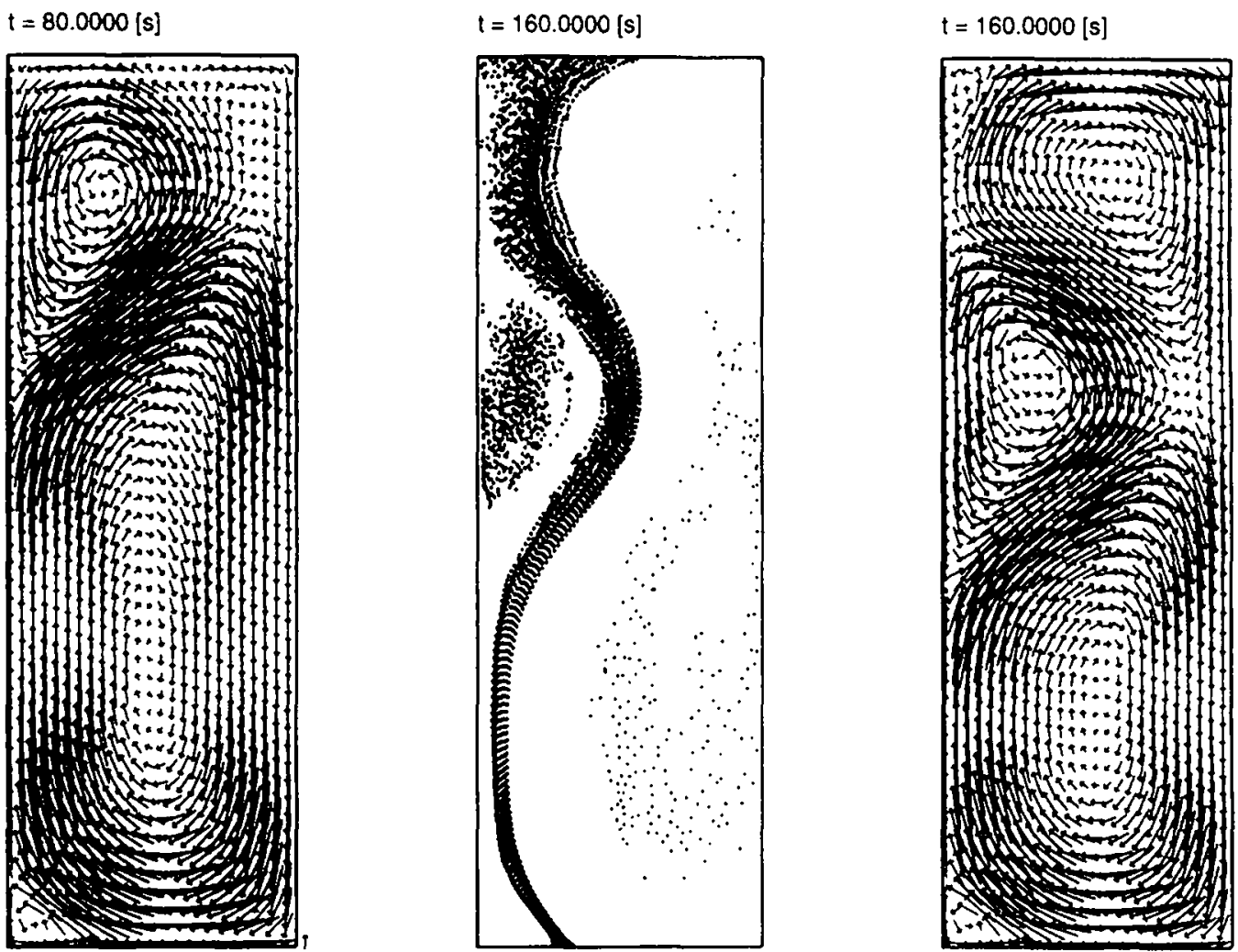

Fig. 3. Instantaneous bubble configuration and associated liquid velocity field at three different time levels. Simulation of experiment by Becker et al. $(1995)$. Gas flou rate $=8.01 \mathrm{~min} 1$. Reference vector $=$ $10.0 \mathrm{~cm} \mathrm{~s}^{-1}$. 
$t=10.0000[s]$

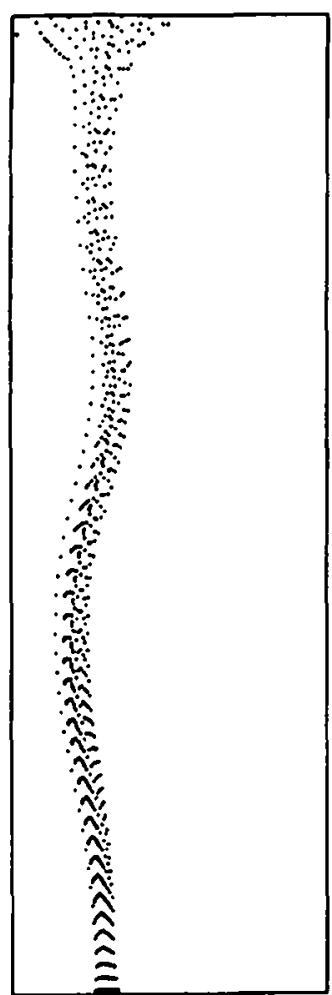

$t=80.0000[s]$

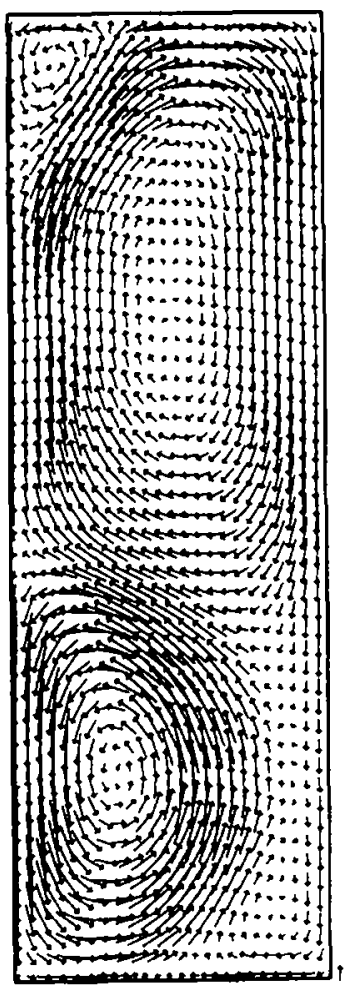

$\mathrm{t}=10.0000[\mathrm{~s}]$

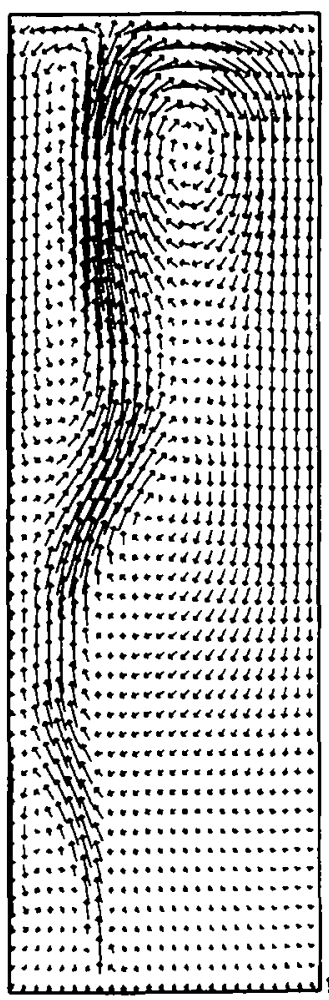

$t=160.0000[s]$

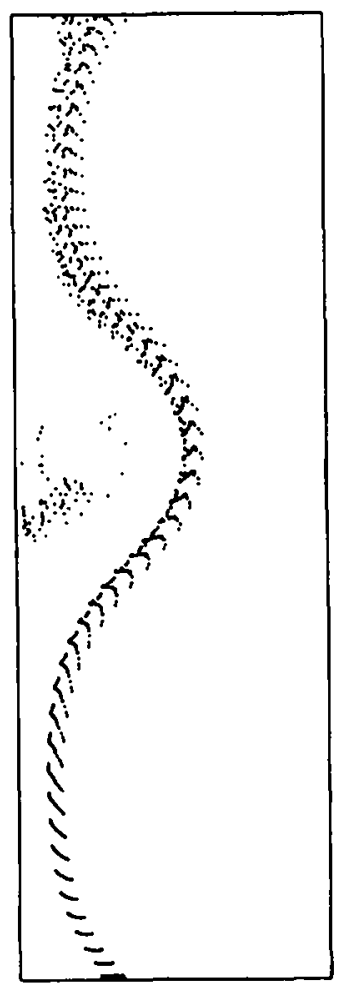

$\mathrm{t}=80.0000[\mathrm{~s}]$

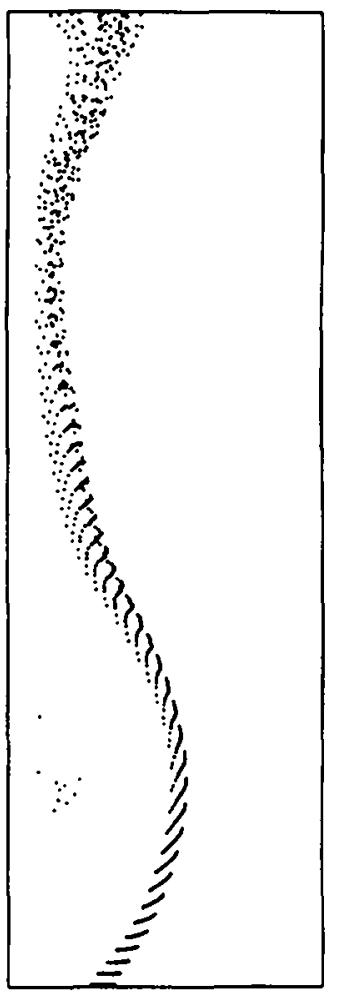

$t=160.0000[s]$

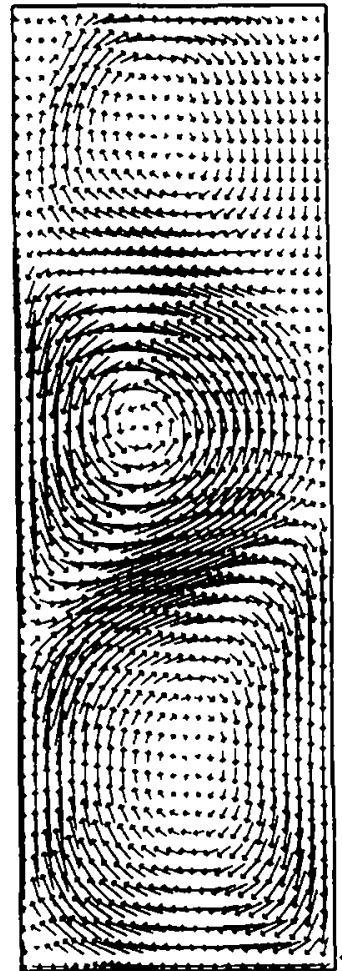

Fig. 4. Instantaneous bubble configuration and associated liquid velocity field at three different time levels. Simulation of experiment by Becker et al. (1995). Gas flow rate $=1.61 \mathrm{~min}^{-1}$. Reference vector $=10.0 \mathrm{~cm} \mathrm{~s}^{-1}$. 


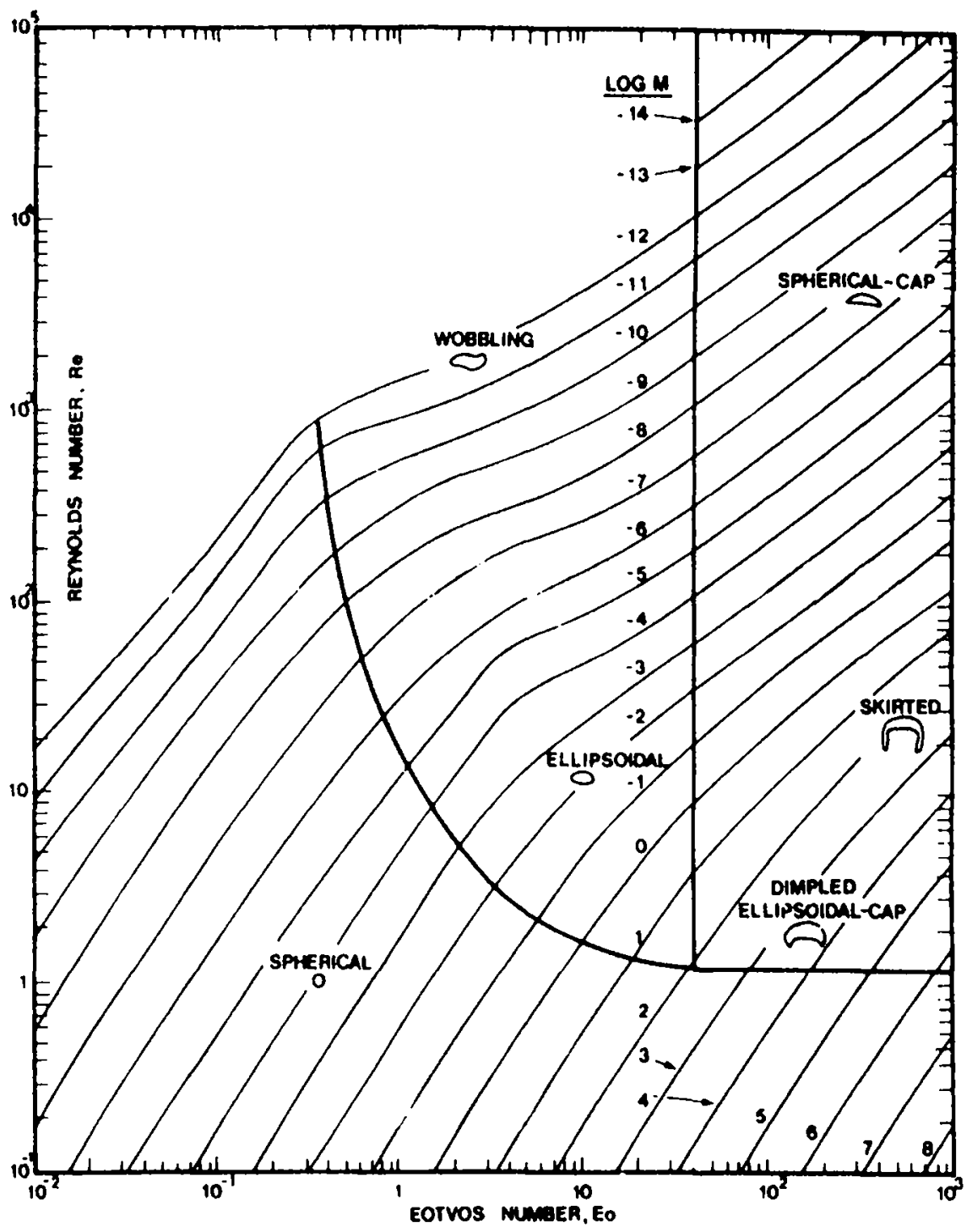

Fig. 5. Graphical correlation by Grace (1973) and Grace et al. (1976) that shows the effect of fluid properties and equivalent bubble diameter on the shape and the terminal rise velocity of bubbles in a quiescent Newtonian liquid.

5.2. Selected results obtained with the VOF model: effect of $\mathrm{Eö}$ and $\mathrm{M}$ number

As discussed previously in Section 4.2, our VOF model resolves the formation and the dynamics of gas bubbles in a quiescent liquid, accounting for changes in the topology of the gas-liquid interface. In particular, the shape of a bubble under the prevailing flow conditions and physical properties of the liquid, is resolved by our model, as well as the gas and liquid flow field associated with this rising bubble. As a first test case for the VOF model, bubble shapes and associated flow patterns were calculated for a wide range of Eötvös and Morton numbers. The correctness of the computational results was assessed with the diagram presented by Grace (1973) and Grace et al. (1976) which shows the effect of fluid properties and equivalent bubble diameter on the bubble shape and on the bubble's terminal rise velocity. This diagram is shown in Fig. 5 for the purpose of reference; the dimensionless Eötvös and Morton numbers are defined as

$$
M=\frac{g \mu^{4} \Delta \rho}{\rho^{2} \sigma^{3}}
$$

and

$$
E o=\frac{g \Delta \rho d_{b}^{2}}{\sigma}
$$

Figure 6 shows a sequence of plots depicting the formation and rise of a single gas bubble emanating from a central orifice at $E \ddot{o}=100$ and $M=2.5 \times$ $10^{-11}$. Both the instantaneous bubble positions as well as the associated flow fields are shown. In accordance with the diagram presented by Grace (1973), the 

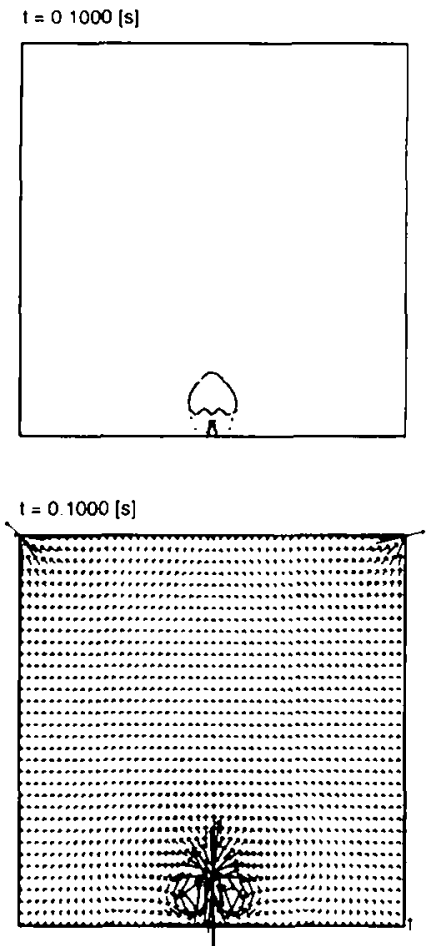

$t=02000: \mathrm{s}]$

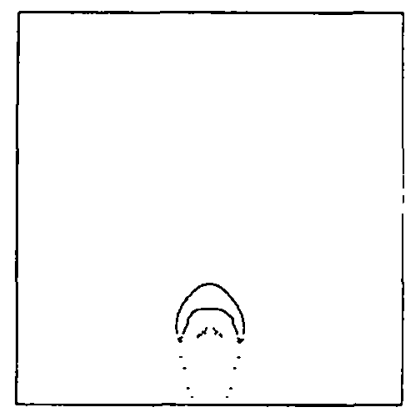

$1=0.2000[s]$

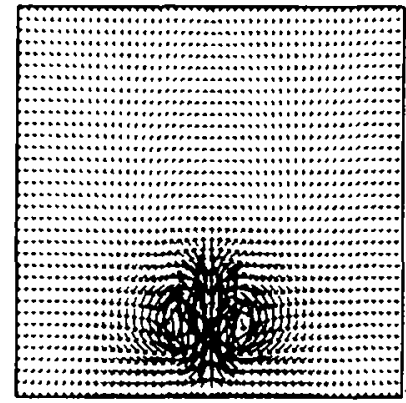

$t=0.5002[s]$
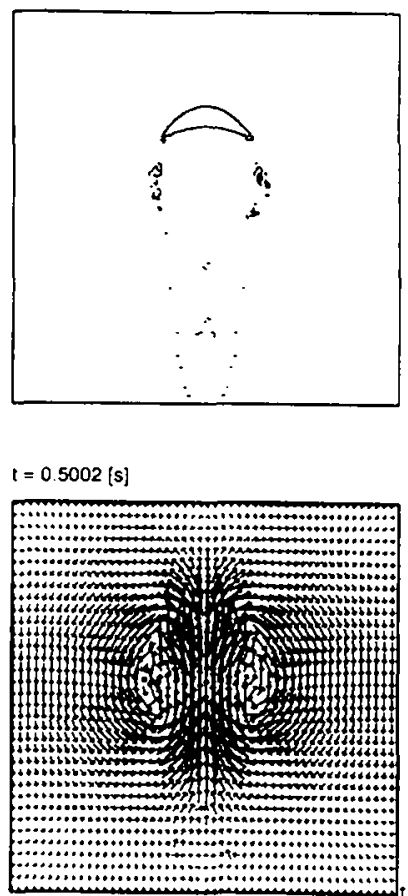

Fig. 6. Formation and rise of a spherical cap shaped bubble emanating from a central orifice at $E \ddot{o}=100$ and $M=2.5 \times 10^{-11}$. Both the instantaneous bubble position and the associated flow field are shown. Reference vector $=10.0 \mathrm{~cm} \mathrm{~s}^{-1}$.

VOF model predicts the formation of a spherical cap shaped bubble, as can clearly be seen from Fig. 6. Moreover, a distinct bubble wake can be inferred from the flow field, which extends downstream of the bubble over a distance of approximately four equivalent bubble diameters.

Figure 7 summarizes a number of snapshots depicting the rise of a single gas bubble at different $E \ddot{O}$ and $M$ numbers. It can clearly be seen that the predicted bubble shapes differ from each other depending on the value of the $E \ddot{o}$ and $M$ numbers. In accordance with the diagram presented by Grace, the VOF model predicts the formation of an cllipsoidal bubble, a skirted bubble and a spherical bubble. In the wake of the skirted bubble, i.e. a region of the flow with high vorticity, it can clearly be seen that small bubbles are shed from the skirts of the bubble under consideration. This is most likely a limitation of the VOF approach, which is known to give inaccurate results for interfaces in a high shear flow (Kothe and Rider. 1995 and Rudman. 1997).

Finally, Fig. 8 depicts the formation and rise of a gas bubble emanating from a central orifice at $E \ddot{o}=2.00$ and $M=2.5 \times 10^{-11}$. A number of consecutive bubble positions is depicted, as well as the flow field associated with the latest bubble position. As can clearly be seen from this figure, the model predicts the formation of a bubble in the wobbling regime, i.e. the bubble exhibits a clear oscillatory motion. This calculated bubble shape strongly resembles the shape expected on basis of the diagram due to Grace. From the flow field, also shown in Fig. 8 , it can be seen that the bubble's oscillatory behavjour is caused by vortices which are shed in an alternating mode at the left and right rear part of the bubble.

As is evident from Figs 6-8, the computed bubble shapes strongly resemble the shapes expected on basis of the diagram presented by Grace (1973). The computed bubble rise velocities of the bubbles depicted in Figs 6-8. however, were found to be significantly lower than the rise velocities inferred from the diagram. For instance, the computed rise velocity of the bubble shown in Fig. 6 is approximately $23 \mathrm{~cm} \mathrm{~s}^{-1}$, whereas the rise velocity inferred from the diagram by Grace (1973) is $37 \mathrm{~cm} / \mathrm{s}$ at $E \ddot{o}=100$ and $M=$ $2.5 \times 10^{-11}$. This is most likely due to the two-dimensional nature of our model and due to the finite lateral dimension of the gas liquid systems studied; whereas the diagram presented by Grace (1973) and Grace et al. (1976) is valid for three-dimensional gas bubbles rising in an unbounded Newtonian liquid. In order to assess the validity of this hypothesis, the effect of the lateral column dimension on the rise velocity of a single bubble was studied. As can be seen from Fig. 9 , an increased bubble rise velocity was found with increasing column width at a fixed equivalent bubble diameter. This is expected behaviour because in a system with relatively small lateral dimensions there is less space for the downward moving liquid induced by the rising gas bubble. This results in higher liquid velocities and thus, increased drag on the bubble. 


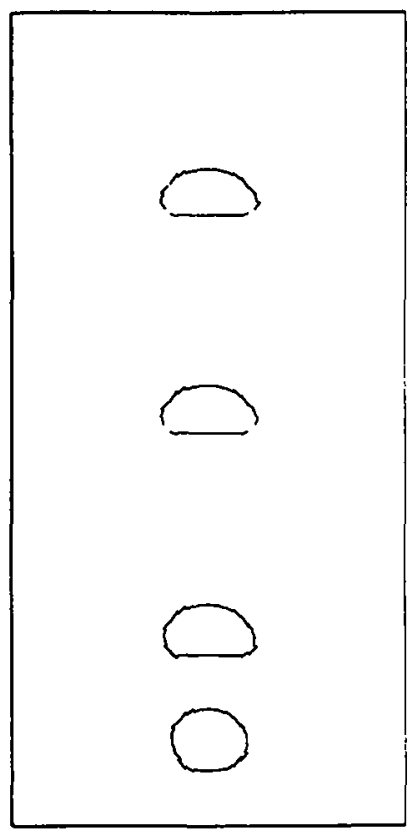

a)

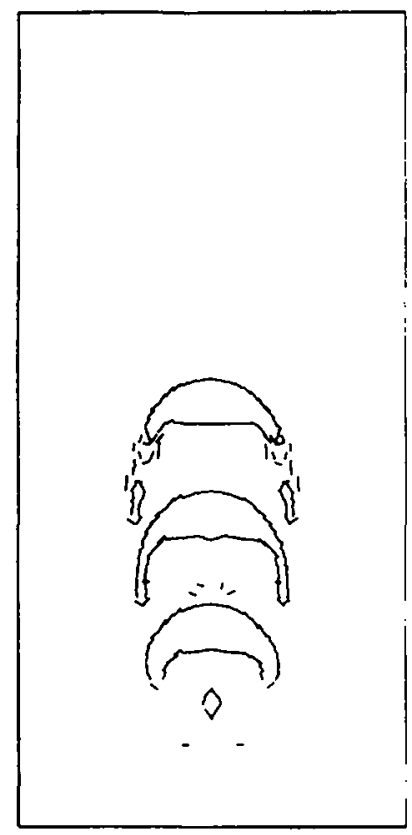

b)

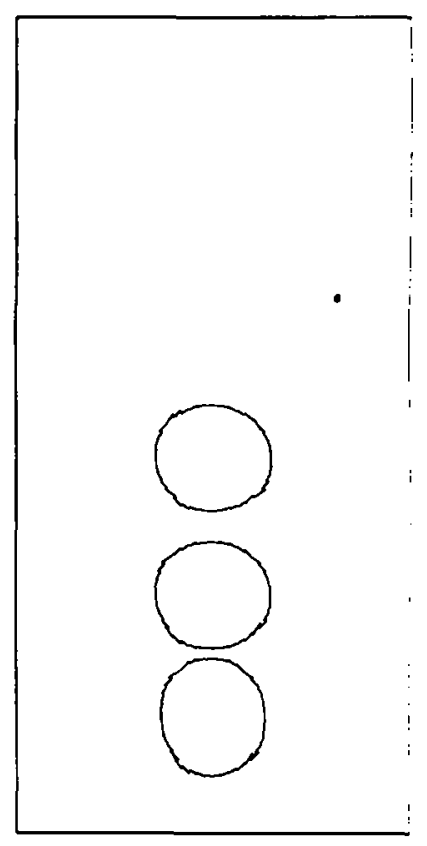

c)

Fig. 7. Formation and rise of a gas bubble emanating from a central orifice at three different time levels. a) $E \ddot{O}=10$ and $M=0.137:$ b) $E \ddot{o}=400$ and $M=100$; 0$) E \ddot{O}=1$ and $M=1.4 \times 10^{-11}$.
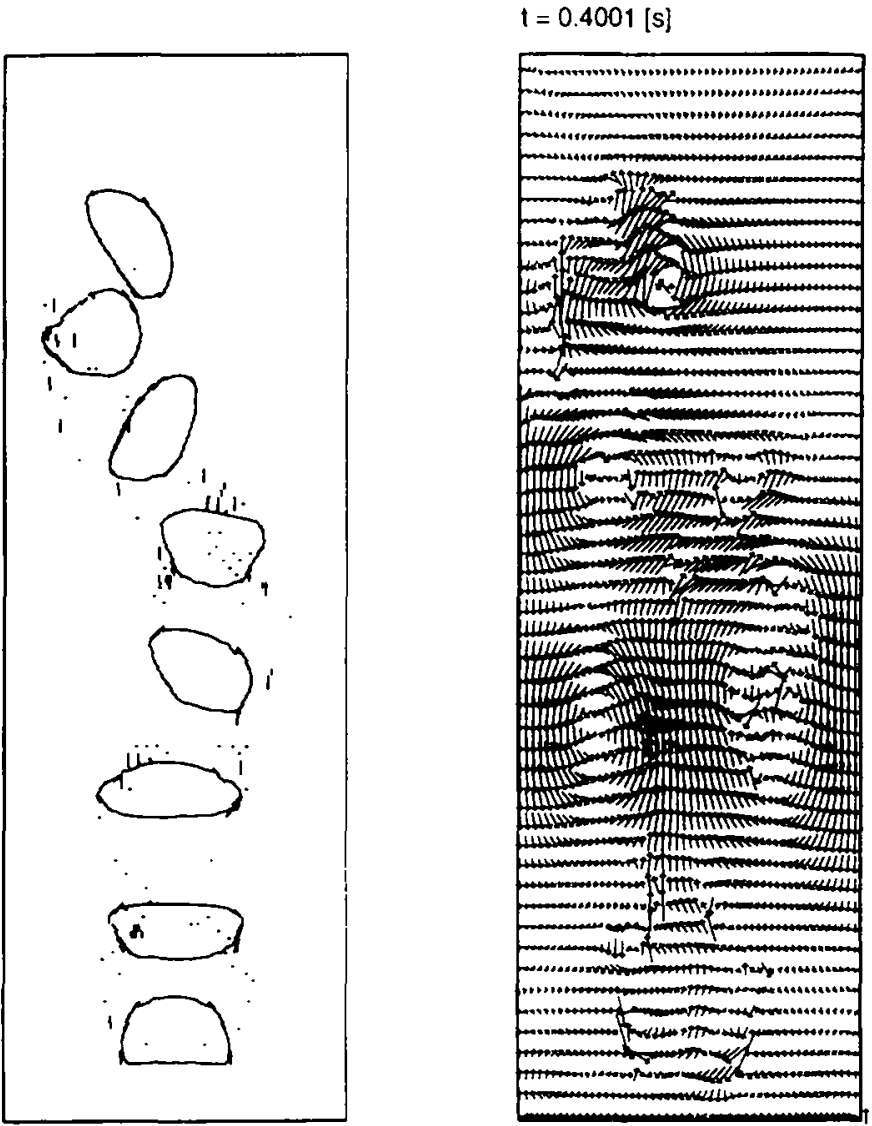

Fig. 8. Formation and rise of a gas bubble emanating from a central orifice at $E \ddot{m}=2.0$ and $M=2.5 \times 10^{-11}$. The instantaneous velocity field associated with the top bubble is also depicted. Reference vector $=10.0 \mathrm{~cm} \mathrm{~s} \quad 1$. 

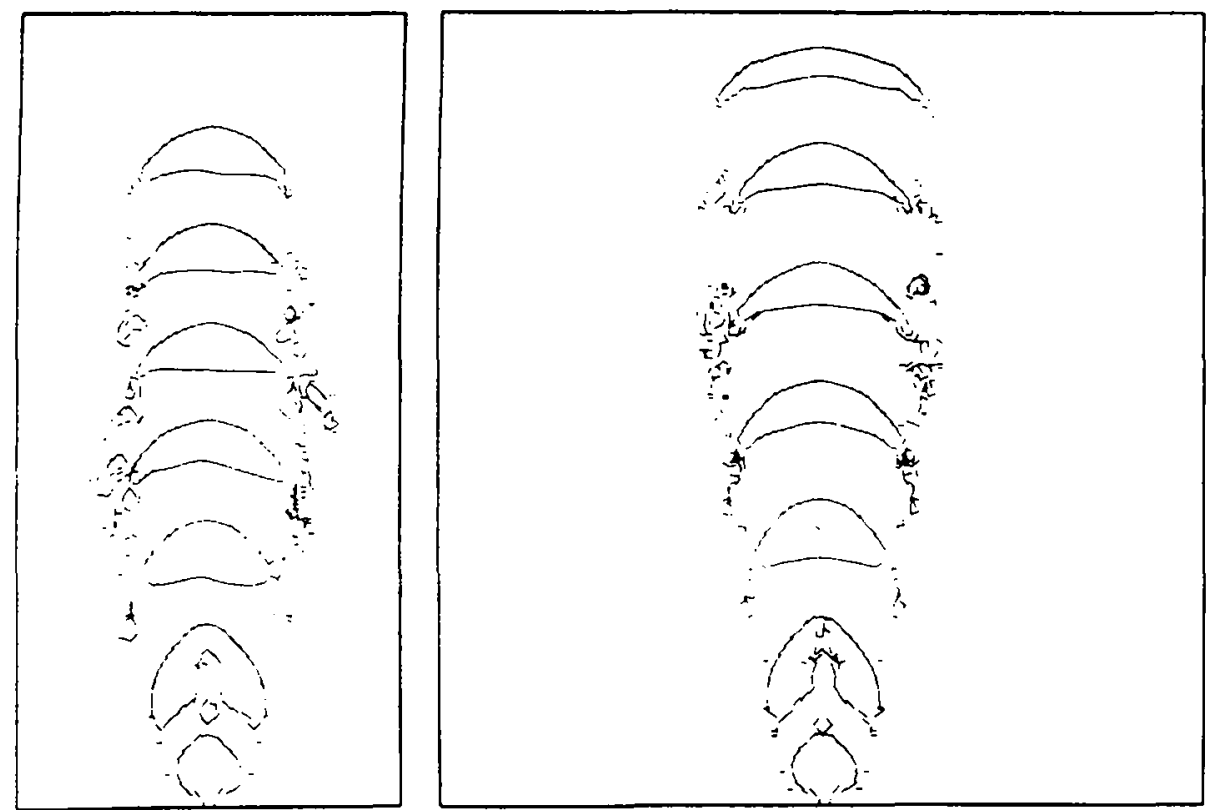

Fig. 9 Effect of column width on bubble rise velocity. The column on the left hand side has a diameter of $10 \mathrm{~cm}$ whereas the column on the right hand side has a diameter of $20 \mathrm{~cm} . E \ddot{o}=100$ and $M=1.0 \times 10^{-12}$

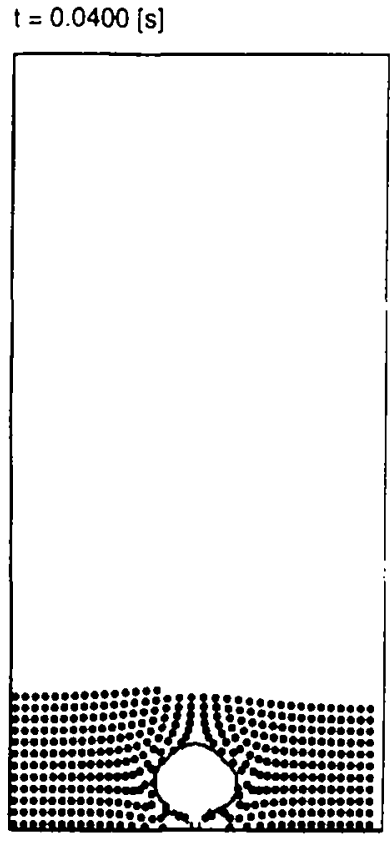

a)

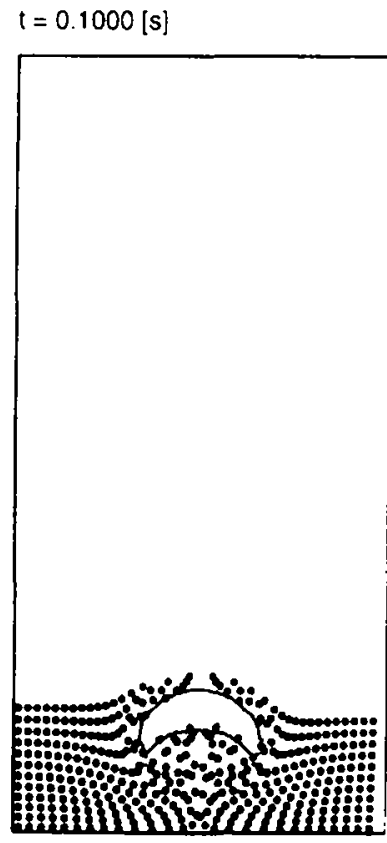

b)

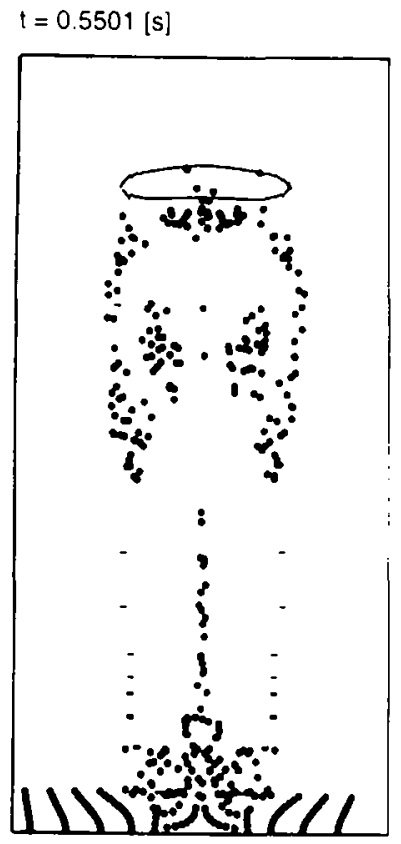

c)

Fig. 10. Three consecutive positions of a gas bubble emanating from a central orifice at $E \ddot{O}=21$ and $M=2.5 \times 10^{-11}$. The instantaneous positions of the neutrally buoyant tracer particles are also shown.

5.3. Selected results obtained with the VOF model: Wake structure

An important characteristic of a gas bubble rising in a quiescent liquid is its wake, which contributes considerably to the mixing in gas-liquid and gasliquid-solid systems. The geometry of the wake of large spherical cap bubbles or circular cap bubbles has been extensively studied in two-dimensional 
$\mathrm{t}=0.5501[\mathrm{~s}]$

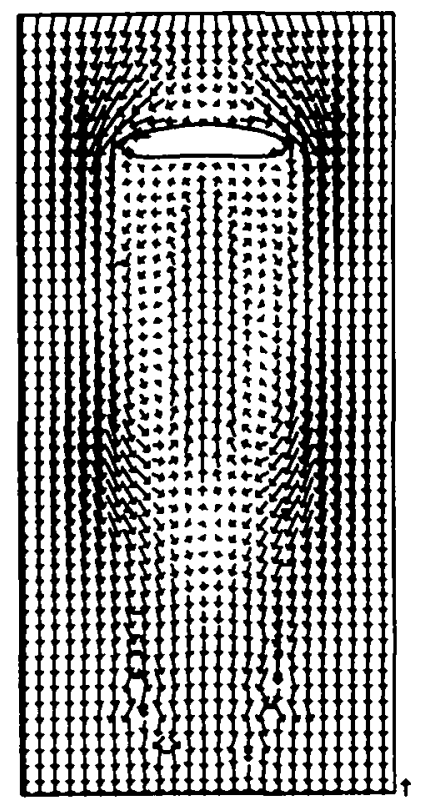

Fig. 11. Instantaneous position of a gas bubble emanating from a central orifice at $L o=21$ and $M=2.5 \times 10^{-11}$. The flow field as seen by an observer moving with the bubble is also shown. Reference vector $=10.0 \mathrm{cms}{ }^{1}$.

gas-liquid systems by among others Crabtree and Bridgwater (1967). Historically, one distinguishes between closed laminar wakes, closed turbulent wakes and open turbulent wakes. The VOF model presented in this paper was used to study the geometry of the wake of a gas bubble rising in a liquid; to achieve this neutrally buoyant tracer particles were added to the liquid and the velocity field as seen by an observer moving with the bubble was calculated from the Fulerian velocity field.

Figure 10 shows three consecutive positions of a gas bubble cmanating from a single orfice; the instantancous positions of the neutrally buoyant tracer particles are also shown. The wake of the bubble can clearly be recognized from Fig. 10(c) as the area behind the bubble that contains a large number of tracer particles. The wake is seen to extend downstream of the bubble over a distance of 4 to 5 bubble diameters. Figure 11 depicts the liquid velocity field seen by an observer moving with the gas bubble. This figure most clearly reveals the geometry of the bubble wake. Video representation of the computed data clearly showed a hydrodynamically stable wake with a well-defined boundary and with two vortices inside; this type of wake is commonly referred to as the closed laminar wake.

\subsection{Selected results obtained with the VOF model: Bubble coalescence}

In addition to the results presented in the previous paragraphs, the VOF model has been used to com- pute the coalescence of two co-axial gas bubbles of equal size which were generated at the same orifice. Figure 12 shows the instantaneous positions of both bubbles. From this sequence of bubble positions it can be seen that the trailing bubble moves faster than the leading bubble and cventually, at $t=0.42 \mathrm{~s}$ coalescence of the two bubbles commences. From computer animations it could clearly be seen that just after completion of the coalescence process (at $t=0.45 \mathrm{~s}$ ) a 'splashing liquid pocket forms at the bubble hase. Due to the fact that the trailing bubble rises in the wake region of the leading bubble, a difference in bubble shape develops. In Fig. 13 the results of the corresponding experiment, reported by Brereton and Korotney (1991). are shown. From a comparison of the theoretical and experimental results one can conclude that a reasonable agreement is obtained. especially in view of the complexity of the coalescence process. Morcover. one should keep in mind that no adjustable parameters were used in the VOF model.

\section{CONCLLSIONS}

In this paper we have presented the "hierarchy of models' concept that offers a powerful tool to study the fluid dynamic behaviour of gas - liquid bubble columns. The size of the column. the length scales of the phenomena of interest and the prevailing flow regime detcrmine the most appropriate model, contained in the 'hierarchy of models: for the problem at hand. Eulerian-Eulerian two fluid models, Eulerian-Lagrangian models and Volume Tracking or Marker Particle models make up this "hierarchy of models'. These models have been briefly reviewed. and their respective advantages and disadvantages have been highlighted. The closure laws in Two Fluid models. the correct description of the various forces acting on a single bubble and the effect of other bubbles on these forces in Eulerian-Lagrangian models have been identified as areas where further research is required.

Fxperimental validation of $\mathrm{CHD}$ results. especially pertaining to multi-phase flows, is very important for the widespread acceptance of CFD in the chemical engineering community. In this respect, particle image velocimetry (PIV) and particle tracking velocimetry (PTV) have been identified as promising experimental techniques that provide quantitative information on the instantaneous structure of the flow. which is typically the type of information obtained from (dynamic) CFD models.

Two different models. a Eulerian Lagrangian model and a Volume Tracking model, developed at Twente University as part of the "hierarchy of models' concept have been presented. The need to incorporate an advanced volume advection algorithm into the Volume Tracking model was emphasized. This advanced advection algorithm has to obtain, and maintain an accurate and sharp representation of the gas liquid interface. 

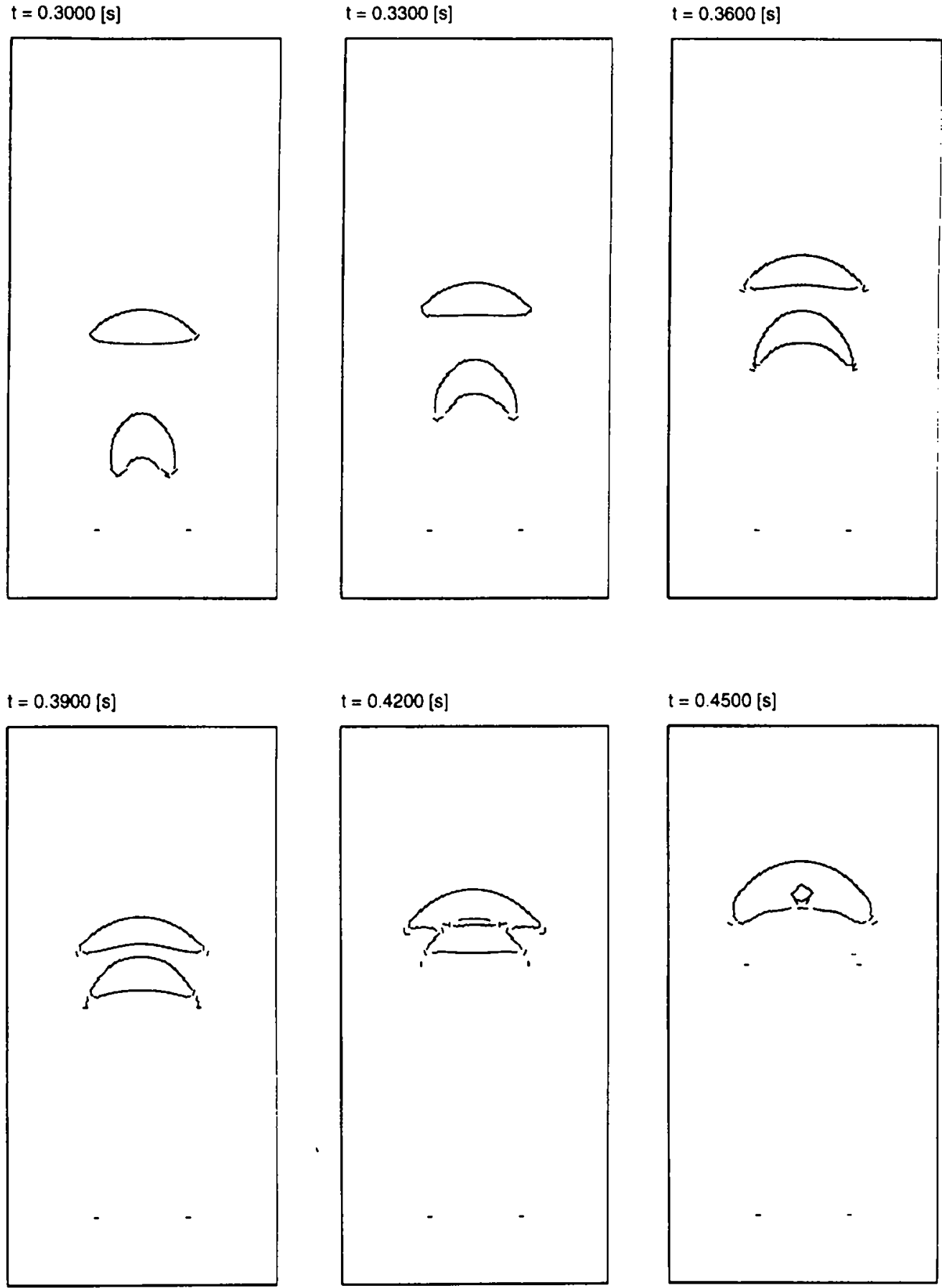

Fig. 12. Instantaneous position of two co-axial gas bubbles at six different time levels. Ë̈ $=16$ and $M=2.0 \times 10^{-4}$

Finally, results obtained with both the EulerianLagrangian model and the Volume Tracking model have been presented. The Eulerian-Lagrangian model could clearly reproduce the experimental results obtained by Becker $e t$ al. (1995) for both the large and small gas velocity cases. The Volume Tracking or VOF model was used to compute bubble shapes and associated flow patterns for a wide range of Eötvös and Morton numbers. The computed bubble shapes strongly resembled the shapes expected on basis of the diagram presented by Grace (1973) and Grace et al. (1976). The VOF model was also used to study the structure of the wake of a gas bubble rising in a quiescent liquid and to study coalescence of two co-axial gas bubbles. This latter result was compared with experimental observations by Brereton and Korotney (1991); a reasonable agreement was obtained, especially in view of the complexity of the coalescence process. 


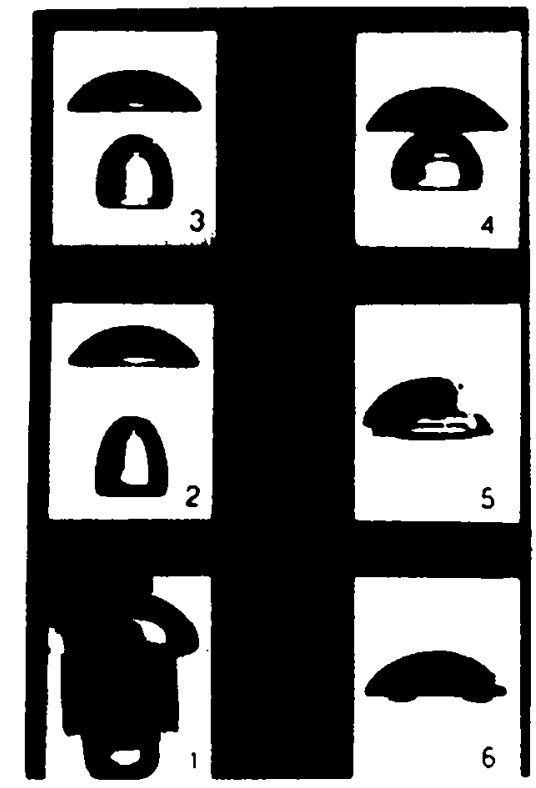

Fig. 13. Experimentally observed coalescence between two co-axial bubbles generated at the same orificc. Experiments by Brereton and Korotney (1991). $E \ddot{O}=16$ and $M=2.0 \times 10^{\circ}$.

\begin{tabular}{|c|c|}
\hline & NOTATION \\
\hline $\mathbf{d}_{b}$ & bubble diameter, $\mathrm{m}$ \\
\hline$E \ddot{~}$ & $\begin{array}{l}\text { dimensionless Eötvös number, dimension- } \\
\text { less }\end{array}$ \\
\hline$F$ & fractional volume liquid, dimensionless \\
\hline $\mathbf{F}_{\boldsymbol{D}}$ & drag force on a bubble, $N$ \\
\hline $\mathbf{F}_{G}$ & force on bubble due to gravity. $\mathrm{N}$ \\
\hline $\mathbf{F}_{L}$ & lift force on bubble, $N$ \\
\hline $\mathbf{F}_{P}$ & force on bubble due to pressure gradient, $\mathrm{N}$ \\
\hline $\mathbf{F}_{\text {total }}$ & total force on a bubble, $\mathrm{N}$ \\
\hline$F_{V, M}$ & virtual mass force on bubble, $\mathrm{N}$ \\
\hline g & acceleration due to gravity, $\mathrm{ms}^{2}$ \\
\hline$M$ & $\begin{array}{l}\text { dimensionless Morton number. dimension- } \\
\text { less }\end{array}$ \\
\hline$m_{b}$ & mass of a bubble, $\mathrm{kg}$ \\
\hline $\mathbf{M}_{k l}$ & $\begin{array}{l}\text { momentum transfer from phase } 1 \text { to phase } \mathrm{k} \text {, } \\
\mathrm{Nm}^{-3}\end{array}$ \\
\hline $\mathbf{n}$ & $\begin{array}{l}\text { normal to gas liquid interface. dimension- } \\
\text { less }\end{array}$ \\
\hline$P$ & pressure, $\mathrm{Nm}^{* 2}$ \\
\hline$R_{b}$ & radius of a bubble, $\mathrm{m}$ \\
\hline$R e_{b}$ & $\begin{array}{l}\text { reynolds number of flow around a bubble. } \\
\text { dimensionless }\end{array}$ \\
\hline$R_{k}$ & $\begin{array}{l}\text { source term in mass conservation equation. } \\
\mathrm{kg} \mathrm{m} \mathrm{m}^{-3} \mathrm{~s}^{-1}\end{array}$ \\
\hline $\mathbf{S}_{k}$ & $\begin{array}{l}\text { source term in momentum conservation } \\
\text { equation, } \mathrm{Nm}\end{array}$ \\
\hline $\mathbf{u}$ & liquid velocity, $\mathrm{ms}^{-1}$ \\
\hline $\mathbf{u}_{k}$ & velocity phase $\mathrm{k} . \mathrm{m} \mathrm{s}^{-1}$ \\
\hline $\mathbf{v}$ & velocity of bubble, $\mathrm{ms}{ }^{\prime}$ \\
\hline$V_{n}$ & volume of a bubble. $\mathrm{m}^{3}$ \\
\hline $\mathbf{x}$ & position of bubble. $m$ \\
\hline & \\
\hline$\dot{\partial t}$ & time step, s \\
\hline$\delta x$ & grid size in $x$ direction, $\mathrm{m}$ \\
\hline
\end{tabular}

$\varepsilon_{1} \quad$ volume fraction liquid in computational cell. dimensionless

$\kappa \quad$ surface curvature, $m$

$\mu_{\mathrm{i}} \quad$ shear viscosity liquid, $\mathrm{kg} \mathrm{m}^{-1} \mathrm{~s}^{-1}$

$\rho_{g} \quad$ density gas phase, $\mathrm{kg} \mathrm{m}^{-3}$

$\rho_{k} \quad$ density phase $\mathrm{k}, \mathrm{kgm}{ }^{* 3}$

$\rho_{l} \quad$ density liquid phase, $\mathrm{kg} \mathrm{m}$ "

$\sigma \quad$ surface tension coefficient, $\mathrm{N} \mathrm{m}^{-1}$

$\tau_{1} \quad$ stress tensor liquid, $\mathrm{N} \mathrm{m}^{-2}$

Abbreviations

CARPT computer automated radio-active particle tracking

CFD computational fluid dynamics

CSF continuum surface force model

DPIV digital particle image velocimetry

HWA hot-wire anemometry

LDA laser doppler anemometry

PLV pulsed light velocimetry

PTV particle tracking velocimetry

RPT ratio-active particle tracking

VOF volume-of-fluid model

TVD total variation diminution

\section{REHERENCES}

Adrian, R. J. (1991) Particle-imaging techniques for experimental fluid mechanics. Ann. Rer. Fluid Mech. 23, $261 \cdot 304$.

Auton, T. R. (1983) The dynamics of bubbles, drops and particles in motion in liquids. Ph.D. thesis, University of Cambridge, Cambridge.

Becker, S., Sokolichin. A. and Eigenberger, G. (1995) Gas liquid fow in bubble columns and loop reactors: part Il. Comparison of detailed experiments and flow simulations. Chem. Engng Sci. 49. 5747.

Brackbill. J. U.. Kothe, D. B. and Zemach, C. (1992) A continuum method for modelling surface tension. J. Comput Phis. 100. 335.

Brereton. G. and Korotney, D. (1991) Co-axial and oblique coalescence of two rising bubbles. In $D_{y}$ namic's of Bubbles and Vortices near a Free Surface. Vol. 1

Chen, R. C. and Fan, L. S. (1992) Particle image velocimetry for characterizing the flow structures in three-dimensional gas-liquid-solid fluidized beds. Chem. Engng Sci. 47, 3615 .

Crabtree, J. R. and Bridgwater, J. (1967) The wakes behind two-dimensional air bubbles. Chem. Engng Sci. 22, 1517.

Cuvelier, C.. Segal, A. and van Steenhoven. A. A. (1986) Finite Element Methods and Natier-Stokes Equations. Rcidel. Dordrecht.

Delnoij, F... Lammers. F. A.. Kuipers, J. A. M. and van Swaaij. W. P. M. (1997a) Dynamic simulation of dispersed gas liquid two-phase flow using a discrete bubble model. Chem. Engng Sci. 52(9), 1429.

Delnoij, E., Kuipers, J. A. M. and van Swaaij, W. P. M. (1997b) Simulation of bubble dynamics in gas licpuid two-phase flow using the volume of fluid (VOF) Method. To be published.

Devanathan. N.. Moslemian. D) and Dudukovicz. M. P. (1990) Flow mapping in bubble columns using CARPT. Chem. Engng Sci. 45. 2285. 
Devanathan, N., Dudukovic, M. P., Lapin, A. and Lübbert, A. (1995) Chaotic flow in bubble column reactors. Chem. Engng Sci. 50, 2661.

Gasche, H. E., Edinger, C., Kömpel, H. and Hofmann (1990) A fluid-dynamically based model of bubble column reactors. Chem. Engng Technol. 13, 341.

Gharib, M., Hernan, M. A., Yavrouian, A. H. and Sarohia, V. (1985) Flow velocity measurement by image processing of optically activated tracers. AIAA paper No. 85-0172.

Grace, J. R. (1973) Shapes and velocities of bubbles rising in infinite liquids. Trans. Inst. Chem. Engng 51,116 .

Grace, J. R., Wairegi, T. and Nguygen, T. H. (1976) Shapes and velocities of single drops and bubbles moving freely through immiscible liquids. Trans. Inst. Chem. Engng 54, 167.

Grienberger, J. and Hofman, H. (1992) Investigations and modelling of bubble columns. Chem. Engng Sci. 47, 2215.

Hirt, C. W. and Nichols, B. D. (1981) Volume of fluid (VOF) method for the dynamics of free boundaries. J. Comput. Phys. 39, 201.

Hjertager, B. H. and Morud, K. (1995) Computational fluid dynamics of bioreactors. Mod. Indent. Control 16, 177.

Hoffmann, A. C. and van den Boggard, H. A. (1995) A Numerical investigation of bubbles rising at intermediate Reynolds and large Weber numbers. Ind. Engng Chem. Res. 34, 366.

Kothe, D. B. and Rider, W. J. (1995) Comments on modeling interfacial flows with volume-of-fluid methods. Technical Report LA-UR-3384. Los Alamos National Laboratory, Available on World Wide Web at http://www.c3.lanl.gov/ wjr/pubs. html.

Kuipers, J. A. M., van Duin, K. J., van Beckum, F. P. H. and van Swaaij, W. P. M. (1993) Computer simulation of the hydrodynamics of a two dimensional gas-fluidized bed. Comput. Chem. Engng. 17, 839.

Lapin, A. and Lübbert, A. (1994) Numerical simulation of the dynamics of two phase gas-liquid flows in bubble columns. Chem. Engng Sci. 49, 3661.

Larachi F., Cassanello, M., Chaouki, J. and Guy, C. (1996) Flow structure of the solids in a 3-D gas-liquid-solid fluidized bed. A.I.Ch.E. J. 42, 2439.

Lin, T. J., Reese, J., Hong, T. and Fan, L. S. (1996) Quantitative analysis and computation of twodimensional bubble columns. A.I.Ch.E. J. 42, 301.

Nichois, B. D., Hirt, C. W. and Hotchkiss, R. S. (1980) SOLA-VOF: a solution algorithm for transient fluid flow with multiple free boundaries. Los Alamos Scientific Laboratory Report LA-8355.
Ranade, V. V. (1992) Flow in bubble column: some numerical experiments. Chem. Engng Sci.47, 1857.

Reese, J. and Fan, L. S. (1994) Transient flow structure in the entrance region of a bubble column using particle image velocimetry. Chem. Engng $S$ ci. 49(24B). 5623.

Rudman, M. (1997) Volume-tracking methods for interfacial flow calculations. Int. J. Numer. Meth. Fluids 24, 671.

Ryskin, G. and Leal, L. G. (1984a) Numerical solution of free-boundary problems in fluid mechanics. Part I. The finite difference technique. J. Fluid Mech. 148, 1

Ryskin, G. and Leal, L. G. (1984b) Numerical solution of free-boundary problems in fluid mechanics. Part II. Buoyancy-driven motion of a gas bubble through a quiescent liquid. J. Fluid Mech. 148, 19-35.

Ryskin, G. and Leal, L. G. (1984c) Numerical solution of free-boundary problems in fluid mechanics. Part III. Bubble deformation in an axisymmetric straining flow. J. Fluid Mech. 148, 37.

Shah. Y. T., Kelkar, B. G., Godbole, S. P. and Deckwer, W.-D. (1982) Design parameter estimates for bubble column reactors. A.I.Ch.E. J. 28, 353.

Sokolichin, A., Eigenberger, G., Lapin, A. and Lübbert, A. (1997) Dynamic numerical simulation of gas-liquid two-phase flows, Euler/Euler versus Euler/Lagrange. Chem. Engng Sci. 52(4), 611.

Sokolichin, A. and Eigenberger, G. (1994) Gas-liquid flow in bubble columns and loop reactors. Part 1 . Detailed modelling and numerical simulation. Chem. Engng Sci. 49, 5735.

Tomiyama, A., Zun, I., Sou, A. and Sakaguchi, T. (1993) Numerical analysis of bubble motion with the VOF method. Nuclr. Engng Des. 141, 69.

Torvik, R. and Svendsen, H. F. (1990) Modelling of slurry reactors, a fundamental approach. Chem. Engng Sci. 45, 2325.

Trapp, J. A. and Mortensen, G. A. (1993) A discrete particle model for bubble slug two phase flow, $J$. Comput. Phys. 107, 367.

Welch, J. E., Harlow, F. H., Shannon, J. P. and Daly, B. J. (1965) The MAC Method: A Computing Technique for Solving Viscous Incompressible Transient Fluid Flow Problems Involving Free Surfaces. Los Alamos Scientific Laboratory Report LA-3425.

Westerweel, J. (1993) Digital particle image velocimetry-theory and application. Ph.D. thesis. Delft University.

Youngs, D. L. (1982) Time-dependent multi-material flow with large fluid distortion. In Numerical Methods for Fluid Dynamics, eds. K. W. Morton and M. J. Bianes, p. 273. Academic Press, New York. 